\title{
Effect of various surfactants on stability and thermophysical properties of nanofluids
}

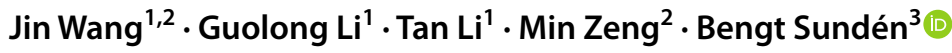

Received: 4 September 2019 / Accepted: 22 January 2020 / Published online: 12 February 2020

(c) The Author(s) 2020

\begin{abstract}
The effect of $\mathrm{Fe}_{3} \mathrm{O}_{4}$ nanoparticles and carbon nanotubes (CNTs) on the viscosity of a nanofluid is experimentally investigated from 278 to $313 \mathrm{~K}$ by changing the nanoparticle volume fraction. These nanoparticles were put into distilled water with various surfactants, i.e., Colace (docusate sodium), trisodium citrate dihydrate (TSC), polyvinyl pyrrolidone, cetyl trimethylammonium bromide, tetramethylammonium hydroxide (TMAH), acacia senegal (GA), sodium dodecyl benzene sulfonate, sodium dodecyl sulfate (SDS), and sodium laurylsulfonate (SLS). Based on the present measurements, new empirical formulas are proposed for $\mathrm{Fe}_{3} \mathrm{O}_{4}$-water, $\mathrm{CNT}$-water and $\mathrm{Fe}_{3} \mathrm{O}_{4}-\mathrm{CNT}$-water nanofluids to provide accurate predictions for the nanofluid viscosity. Based on the viscosity testing, stabilities and thermal conductivities of $\mathrm{Fe}_{3} \mathrm{O}_{4}-\mathrm{TMAH}, \mathrm{Fe}_{3} \mathrm{O}_{4}-\mathrm{Colace}$, $\mathrm{Fe}_{3} \mathrm{O}_{4}-\mathrm{TSC}$, CNT-SDS, CNT-GA, $\mathrm{Fe}_{3} \mathrm{O}_{4}-\mathrm{CNT}-\mathrm{SLS}$, and $\mathrm{Fe}_{3} \mathrm{O}_{4}-\mathrm{CNT}-\mathrm{TSC}$ nanofluids with a volume concentration of $0.5 \%$ are investigated in the present research. Results indicate that better stability, smaller viscosity, and higher thermal conductivity are obtained, when the surfactants TMAH, SDS, and SLS are added into the $\mathrm{Fe}_{3} \mathrm{O}_{4}$-water, CNT-water, and the $\mathrm{Fe}_{3} \mathrm{O}_{4}-\mathrm{CNT}$-water nanofluid, respectively. The CNT-water and $\mathrm{Fe}_{3} \mathrm{O}_{4}-\mathrm{CNT}$-water nanofluids exhibit a shear-thinning behavior, whereas a linear rheological behavior can be observed by water-based Colace- $\mathrm{Fe}_{3} \mathrm{O}_{4}, \mathrm{TMAH}-\mathrm{Fe}_{3} \mathrm{O}_{4}$, and TSC$\mathrm{Fe}_{3} \mathrm{O}_{4}$ nanofluids.
\end{abstract}

Keywords Nanofluid · Thermal conductivity $\cdot$ Carbon nanotube $\cdot$ Viscosity $\cdot$ Surfactant

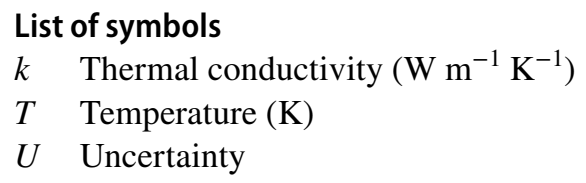

1 School of Energy and Environmental Engineering, Hebei University of Technology, Tianjin 300401, China

2 Key Laboratory of Thermo-Fluid Science and Engineering (Xi' an Jiaotong University), Ministry of Education, Xi' an 710049, China

3 Department of Energy Sciences, Division of Heat Transfer, Lund University, 22100 Lund, Sweden

\author{
Greek symbols \\ $\theta \quad$ Surfactant ratio fraction \\ $\mu \quad$ Dynamic viscosity (Pa s) \\ $\varphi$ Nanoparticle volume fraction \\ Subscripts \\ f Base fluid \\ nf Nanofluid
}

\section{Introduction}

Nanofluids as a stable colloidal suspension are prepared by dispersing nanoparticles in base fluids, such as water, ethylene glycol, and oil. Nanofluids have promising broad prospects in biomedical, optical, and sensor devices [1,2]. Nanofluids are attracting much attention because they offer good heat transfer properties to surpass the performance of conventional fluids. Rashidi et al. [3] reviewed condensation and evaporation performances of various nanofluids. They summarized that deposition and suspension of nanoparticles should be considered, when the efficiency of the thermal system was analyzed. Rashidi et al. [4] reviewed 
an effect of nanofluids on productivities of solar distillation systems. They reported that the daily productivities of the solar distillation systems increased with the volume concentration of the nanofluid. Sundar et al. [5] investigated effects of MWCNT- $\mathrm{Fe}_{3} \mathrm{O}_{4}$-water hybrid nanofluids on turbulent forced convection in a heated tube. They observed that Nusselt number of the nanofluid with $0.3 \%$ particle concentration was improved by $31.10 \%$ at Reynolds number of 22000 . Yarmand et al. [6] experimentally investigated heat transfer performance of graphene nanoplatelet (GNP)-Ag-water nanofluid under turbulent flow in a circular tube. It was found that heat transfer performance of the 0.1 mass\% GNP-Ag-water nanofluid was enhanced by $32.7 \%$ at Reynolds number of 17500. Chen et al. [7] studied heat transfer of various EGW (ethylene glycol aqueous solution)-based nanofluids filled in an electric heater. Results indicated that the heating performance of the 2.0 mass \% $\mathrm{Cu}$-EGW nanofluid increased by $13.18 \%$ compared to the base fluid.

In the past two decades, most researchers devoted themselves to the research on physical properties of nanofluids, mainly including nanofluid viscosity and thermal conductivity. Many studies on thermal conductivity of nanofluids have been carried out.

Thermal conductivity of water-ethylene glycol-based graphene oxide (GO) nanofluids was analyzed by Izadkhah et al. [8] using the classical molecular dynamics theory, and they found that the simulated results agreed well with theoretical models. Ranjbarzadeh et al. [9] experimentally studied the thermal conductivity of water-based silica nanofluid with different solid volume fractions and temperatures. It was observed that thermal conductivity of $3 \mathrm{vol} \%$ silica nanofluid increased by $38.2 \%$ at $55{ }^{\circ} \mathrm{C}$ compared to the base fluid. Akhgar and Toghraie [10] investigated effects of volume fraction and temperature on thermal conductivity of water-ethylene glycol- $\mathrm{TiO}_{2}-\mathrm{MWCNT}$ hybrid nanofluid, and they found that compared with the base fluid, the thermal conductivity of the 1 vol\% hybrid nanofluid was enhanced by $38.7 \%$ at $55{ }^{\circ} \mathrm{C}$. In addition, the viscosity of a nanofluid shows significant influence on the heat transfer enhancement, and many researchers focused their interests in the nanofluid viscosity, and they found that the viscosity of the nanofluid was affected by the nanoparticle size, volume fraction, shear rate, temperature, and aggregate size. Abbasi et al. [11] investigated rheological behaviors of various nanofluids. They found that high portion of multi-walled carbon nanotubes (MWCNTs) resulted in high viscosity of the MWCNT- $\mathrm{TiO}_{2}$ nanofluid. Esfe et al. [12] experimentally analyzed the viscosity of the $\mathrm{Mg}(\mathrm{OH})_{2}$-ethylene glycol nanofluid at various temperatures and shear rates. It was found that the ratio of nanofluid viscosity to water viscosity reach to a minimum value at $35^{\circ} \mathrm{C}$. Kole and Dey [13] reported effects of shear strain rate and temperature on the viscosity of the graphene-based nanofluid. It was concluded that no classical models successfully explained the observed viscosity enhancement with the functionalized hydrogen exfoliated graphene (f-HEG) loading at room temperature. Omrani et al. [14] measured viscosity of multi-walled carbon nanotube water-based nanofluid. Results revealed that a maximum viscosity increase of $5.5 \%$ was achieved for $0.05 \mathrm{vol} \%$ nanoparticle concentration at $45{ }^{\circ} \mathrm{C}$. Rudyak and Krasnolutskii [15] analyzed effects of nanoparticle size (1-4 nm) and volume concentration (1-12\%) on the nanofluid viscosity. They found that the viscosity of the nanofluid depended on the nanoparticle material and decreased with an increase in the particle size. Wang et al. [16] experimentally studied effects of magnetic field, solid volume concentration, and temperature on viscosity of a $\mathrm{Fe}_{3} \mathrm{O}_{4}$-water nanofluid. It was observed that compared with $0.5 \mathrm{vol} \%$ nanofluid, the viscosity of $5.0 \mathrm{vol} \% \mathrm{Fe}_{3} \mathrm{O}_{4}$ nanofluid increased by $22.5 \%$ at $293 \mathrm{~K}$. Yang et al. [17] proposed a theoretical model to predict viscosity of water-based Newtonian nanofluids. The predicted results from their model showed a good agreement with experimental results. Hajiyan et al. [18] conducted an investigation on viscosity of magnetic nanofluids under external magnetic fields. They found that the viscosity of the magnetic nanofluid increased with increasing magnetic field and volume fraction.

The main purpose of this systematic study is to systematically investigate the effect of using various surfactants on the stability and thermophysical properties (viscosity and thermal conductivity) of $\mathrm{Fe}_{3} \mathrm{O}_{4}$-water, CNT-water, and $\mathrm{Fe}_{3} \mathrm{O}_{4}-\mathrm{CNT}$-water nanofluids. Moreover, $\mathrm{Fe}_{3} \mathrm{O}_{4}$ nanoparticles and CNTs are mixed in the ratio 3:1 to synthesize the new $\mathrm{Fe}_{3} \mathrm{O}_{4}-\mathrm{CNT}$-water nanofluid. The temperature dependent viscosity is investigated by considering various volume fractions of nanoparticles.

\section{Nanofluids preparation}

$\mathrm{Fe}_{3} \mathrm{O}_{4}$ particles with a size of 8-20 nm (a density of $5.18 \mathrm{~g} \mathrm{~cm}^{-3}$ ) [19] are used and synthesized by a conventional coprecipitation process. Multi-walled carbon nanotubes (CNTs) were purchased from Chengdu Organic Chemicals company. The scanning electron micrographs (SEM) and transmission electron microscopy (TEM) of CNTs and $\mathrm{Fe}_{3} \mathrm{O}_{4}$ nanoparticles are shown in Fig. 1. The CNTs (99.9\% purity and a density of $2.1 \mathrm{~g} \mathrm{~cm}^{-3}$ ) [20] have an outer diameter of $8-15 \mathrm{~nm}$ and a length of $1-10 \mu \mathrm{m}$. By using potassium persulfate at $\mathrm{pH}$ (potential of hydrogen) $=13$, carbon nanotubes were chemically functionalized to attach an "-OH" group for a homogenous dispersion in the nanofluid. The CNTs were dispersed in the potassium persulfate solution with $\mathrm{PH}=13$ at $85^{\circ} \mathrm{C}$. After a mechanical stirring for $6 \mathrm{~h}$, CNTs show a neutral potential of hydrogen. CNTs samples were placed in a drying oven at $50{ }^{\circ} \mathrm{C}$ for $32 \mathrm{~h}$. 


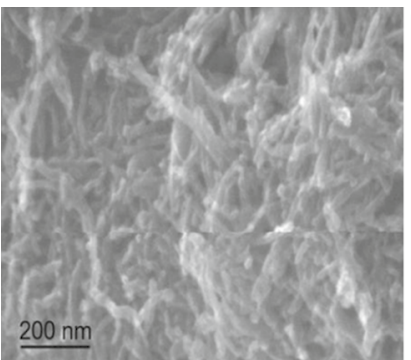

(a) CNTs

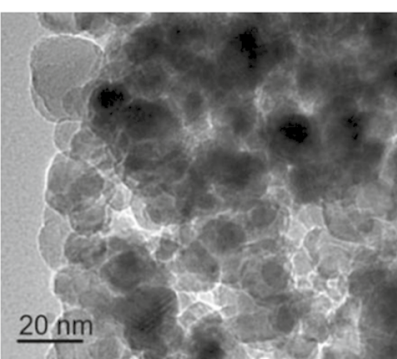

(b) $\mathrm{Fe}_{3} \mathrm{O}_{4}$ nanoparticles
Fig. 1 Images by TEM and SEM

Nanoparticles $\mathrm{Fe}_{3} \mathrm{O}_{4}, \mathrm{CNTs}$, and $\mathrm{Fe}_{3} \mathrm{O}_{4}-\mathrm{CNTs}$ were dispersed in distilled water to synthesize the nanofluids. As a function of temperature and volume fraction of the nanoparticles, the viscosity of the nanofluid is investigated in this paper. A comparison of viscosities for various nanofluids was conducted for three nanoparticle volume fractions $(0 \%, 0.5 \%$, and $1 \%)$ and eight different temperatures $(278 \mathrm{~K}$, $283 \mathrm{~K}, 288 \mathrm{~K}, 293 \mathrm{~K}, 298 \mathrm{~K}, 303 \mathrm{~K}, 308 \mathrm{~K}$, and $313 \mathrm{~K}$ ). The $\mathrm{Fe}_{3} \mathrm{O}_{4}$ nanoparticles were put into the distilled water with various surfactants, i.e., Colace (docusate sodium), trisodium citrate dihydrate (TSC), polyvinyl pyrrolidone (PVP), cetyl trimethylammonium bromide (CTAB), and tetramethylammonium hydroxide (TMAH). For the CNT-water nanofluid, acacia senegal (GA), CTAB, sodium dodecyl benzene sulfonate (SDBS), and sodium dodecyl sulfate (SDS) were used as the surfactants. When both the nanoparticles $\mathrm{Fe}_{3} \mathrm{O}_{4}$ and CNTs were used to synthesize the hybrid nanofluid, the effect of the surfactants on viscosity of the nanofluid was investigated by using GA, TMAH, sodium laurylsulfonate (SLS), and TSC. Figure 2 shows the photographs of $\mathrm{Fe}_{3} \mathrm{O}_{4}$-water, CNT-water, and $\mathrm{Fe}_{3} \mathrm{O}_{4}$-CNT-water nanofluids.

\section{Uncertainty analysis}

The uncertainties of thermal conductivity and viscosity are calculated according to the method suggested by Moffat [21]. In addition, the details of the uncertainty calculations are given in "Appendix 1". The viscosity of nanofluids was measured by a brookfield DV2T viscometer (Brookfield Engineering Laboratories Company, USA). A thermostatic bath was used to control the temperature of test nanofluid. The physical photograph of the viscometer is shown in Fig. 3. Deionized water was used as the standard solution was to calibrate the viscometer. The accuracy in temperature measurements is $\pm 0.1{ }^{\circ} \mathrm{C}\left(-100\right.$ to $\left.149^{\circ} \mathrm{C}\right)$. Accuracy of

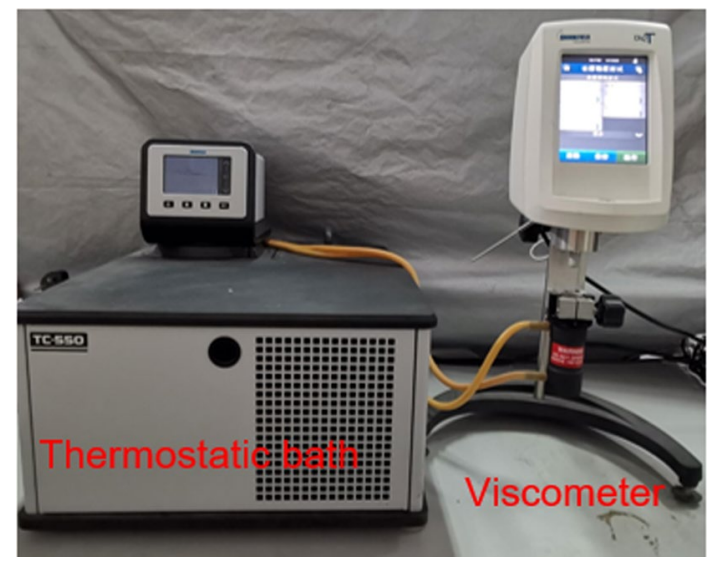

Fig. 3 Real photograph of the viscometer

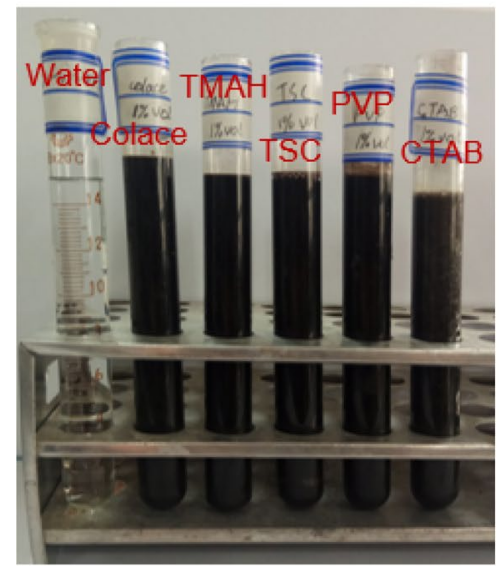

(a) $\mathrm{Fe}_{3} \mathrm{O}_{4}$-water

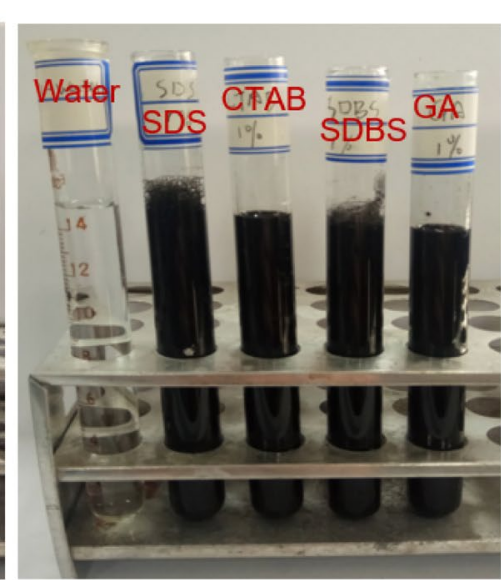

(b) CNTs-water

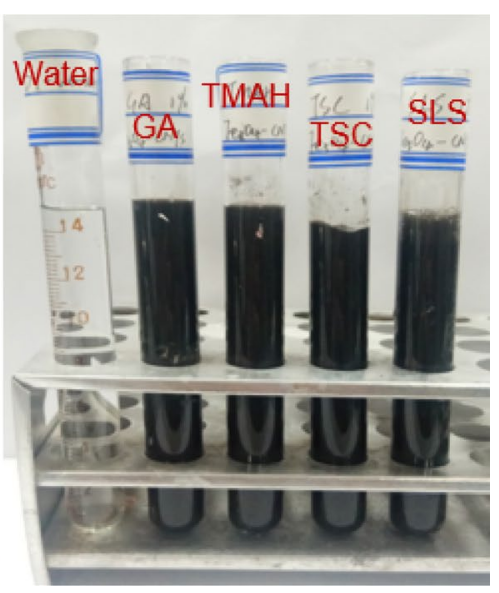

(c) $\mathrm{Fe}_{3} \mathrm{O}_{4}$-CNTs-water

Fig. 2 Photographs of the $1 \%$ vol. nanofluids with different surfactants 
Fig. 4 Real picture of the thermal property analyzer

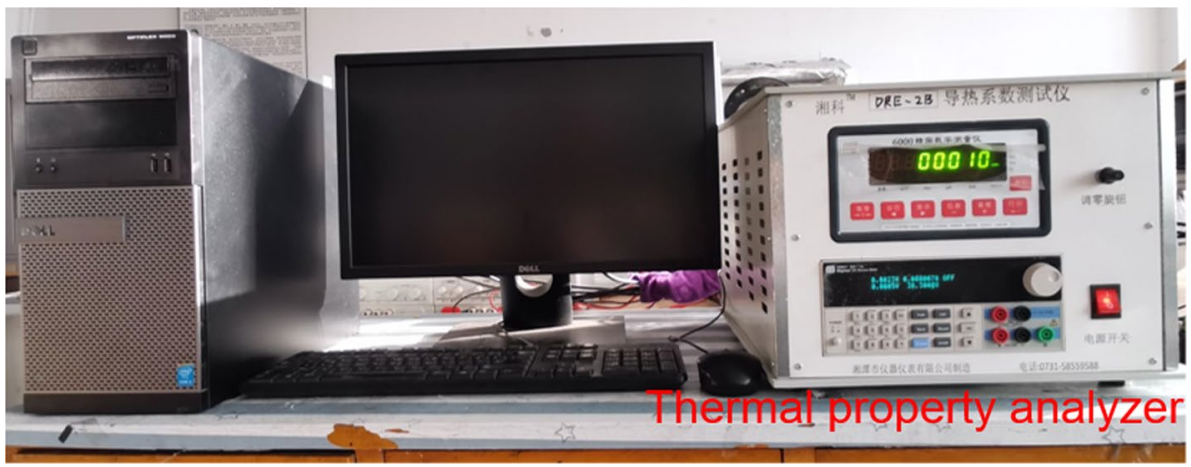

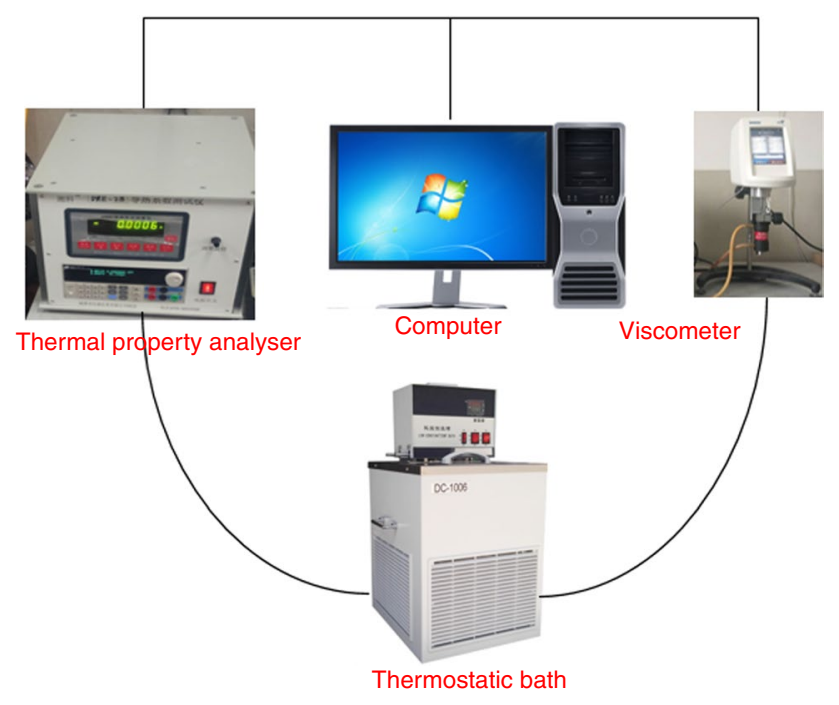

Fig. 5 Schematic diagram of the testing system for thermophysical properties

viscometer is $\pm 1.0 \%$. Therefore, the maximum uncertainty of the viscosity is $2.24 \%$. The uncertainty of the viscosity $\left(U_{\mu}\right)$ is determined by Eq. (1) in Ref. [21]:

$U \mu=\sqrt{\left(\frac{\delta T}{T}\right)^{2}+\left(\frac{\delta \mu_{\mathrm{nf}}}{\mu_{\mathrm{nf}}}\right)^{2}}$

Thermal conductivity of the nanofluid was measured by a DRE-2B thermal property analyzer (Xiangtan Instrument $\&$ Meter Co., Ltd., China). The physical photograph of the thermal property analyzer is shown in Fig. 4. Figure 5 shows a schematic for tests about viscosity and thermal conductivity. The accuracy for the temperature measurement is $\pm 0.1^{\circ} \mathrm{C}$ at $10-40{ }^{\circ} \mathrm{C}$. Accuracy of thermal property analyzer is $\pm 3.0 \%$. The uncertainty of the thermal conductivity is calculated by Eq. (2) in Ref. [21]:

$U k=\sqrt{\left(\frac{\delta T}{T}\right)^{2}+\left(\frac{\delta k_{\mathrm{nf}}}{k_{\mathrm{nf}}}\right)^{2}}$
Table 1 Uncertainty analysis for results

\begin{tabular}{ll}
\hline Variable name & Uncertainty \\
\hline Temperature & $\pm 0.1^{\circ} \mathrm{C}$ \\
Accuracy of viscometer & $\pm 1 \%$ \\
Accuracy of thermal property analyzer & $\pm 3 \%$ \\
Viscosity $(\mu)$ & $\pm 2.24 \%$ \\
thermal conductivity $(k)$ & $\pm 3.16 \%$ \\
\hline
\end{tabular}

Finally, the maximum uncertainty of the thermal conductivity is $3.16 \%$. Table 1 shows the uncertainties of the measured parameters in the present study.

\section{Results and discussion}

\section{Tests of nanofluid viscosities}

The effect of surfactant on thermophysical properties of base fluid (distilled water) is shown in Fig. 6. Compared with the base fluid, the base fluid-TMAH and base fluid-TSC solutions $(\theta=0.1 \%)$ show the maximum enhancements of the viscosities of $0.93 \%$ and $0.96 \%$, respectively. The maximum difference of thermal conductivity between solutions (base fluid-TMAH and base fluid-TSC solution) and base fluid is less than $1.6 \%$ for all the temperatures.

The viscosity values versus shear rate at $25{ }^{\circ} \mathrm{C}$ with different surfactants and volume fractions of nanoparticles are shown in Fig. 7. Water-based Colace- $\mathrm{Fe}_{3} \mathrm{O}_{4}, \mathrm{TMAH}-\mathrm{Fe}_{3} \mathrm{O}_{4}$, and TSC $-\mathrm{Fe}_{3} \mathrm{O}_{4}$ nanofluids have Newtonian behavior in the whole range of shear rate $\left(48.92-110.1 \mathrm{~s}^{-1}\right)$. It is found that for the $0.5 \% \mathrm{Fe}_{3} \mathrm{O}_{4}$-water nanofluid, the average value of viscosity is higher than the base fluid (distilled water) with the value increased by $3 \%(3.2 \%, 5.6 \%$ and $5.8 \%)$, whereas for the $1 \% \mathrm{Fe}_{3} \mathrm{O}_{4}$-water nanofluid, the average viscosity is increased by $5 \%(5.4 \%, 9.5 \%$, and $9.7 \%)$. In addition, the water-based PVP- $-\mathrm{Fe}_{3} \mathrm{O}_{4}$ and $\mathrm{CTAB}-\mathrm{Fe}_{3} \mathrm{O}_{4}$ nanofluids exhibit a non-Newtonian behavior (shear-thinning) in the whole range of the shear rate. The average value of the 
viscosity is higher than the base fluid by more than $70 \%$ (83.3\% and $73.8 \%$ ) for $0.5 \% \mathrm{Fe}_{3} \mathrm{O}_{4}$-water nanofluids and more than $130 \%$ (143.8\% and $134.2 \%$ ) for $1 \% \mathrm{Fe}_{3} \mathrm{O}_{4}$-water nanofluids, respectively.

Figure 8 shows that for all shear rates, the viscosities of water-based SDS-CNT, CATB-CNT, SDBS-CNT, and GA-CNT nanofluids decrease with an increase in the shear rate at $25^{\circ} \mathrm{C}$. It is found that the average viscosity increases by $287.5 \%$ for the $1 \%$ CNT-water nanofluid with the surfactant SDBS, whereas it increases by $160.8 \%$ for the $0.5 \% \mathrm{CNT}$-water nanofluid. It is found that a large shear force results in de-agglomeration of bundled nanotubes and shear-thinning behavior is observed.
Fig. 6 Viscosity and thermal conductivity of base fluid with two surfactants

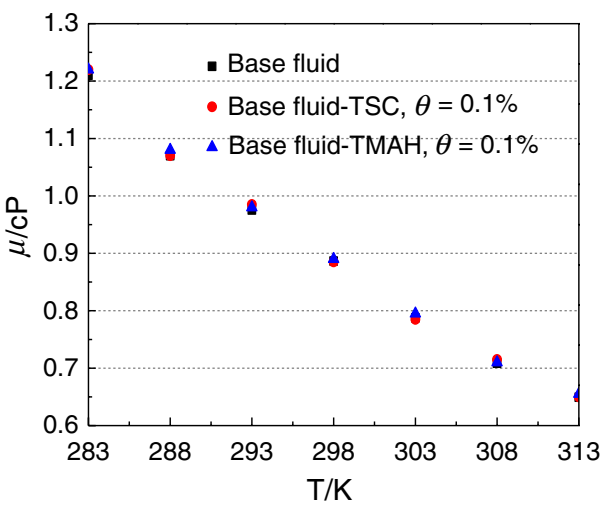

(a) Viscosity

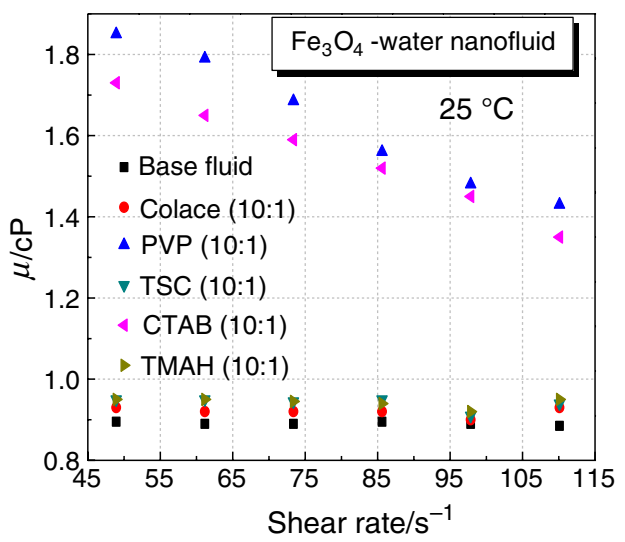

(a) $0.5 \%$ volume fraction

Fig. 7 Viscosity of $\mathrm{Fe}_{3} \mathrm{O}_{4}$-water nanofluids versus the shear rate at different surfactants
Fig. 8 Viscosity of CNT-water nanofluids versus the shear rate at different surfactants

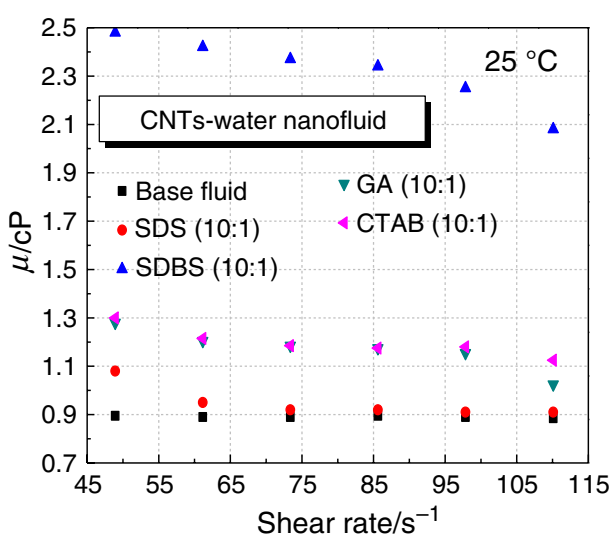

(a) $0.5 \%$ volume fraction

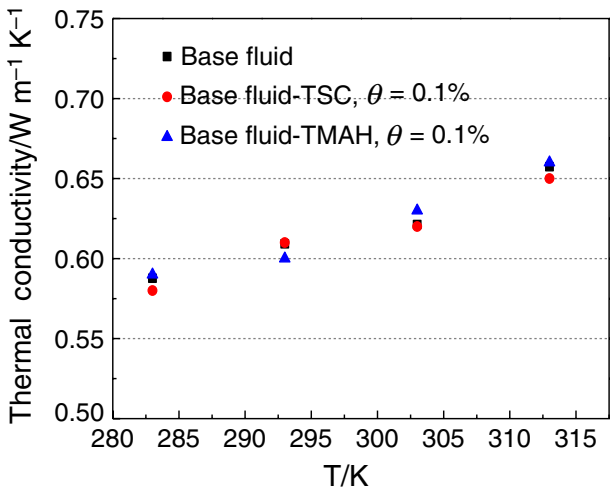

(b) Thermal conductivity

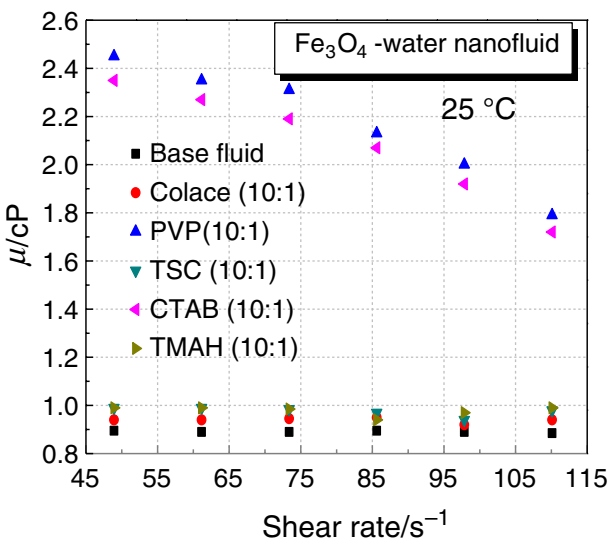

(b) $1 \%$ volume fraction

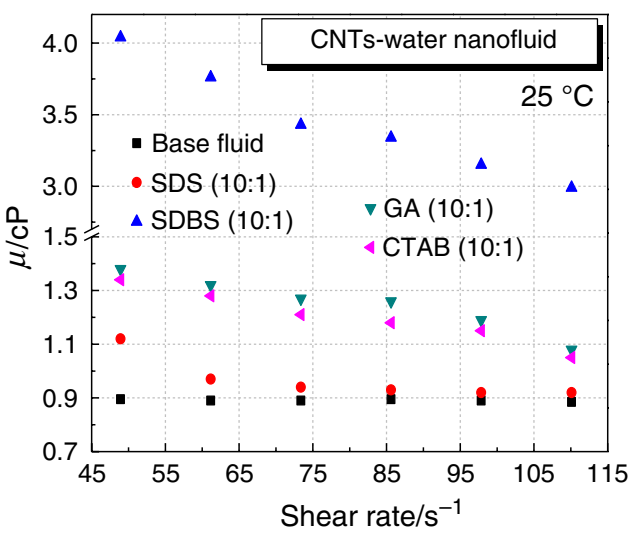

(b) $1 \%$ volume fraction 
Figure 9 shows the relative viscosity dependence on the shear rate for the $\mathrm{Fe}_{3} \mathrm{O}_{4}$-CNT-water nanofluid with various surfactants. The water-based GA- $\mathrm{Fe}_{3} \mathrm{O}_{4}-\mathrm{CNTs}$, TSC- $\mathrm{Fe}_{3} \mathrm{O}_{4}-\mathrm{CNTs}$, SLS-Fe $\mathrm{O}_{4}-\mathrm{CNTs}$, and TMAH- $\mathrm{Fe}_{3} \mathrm{O}_{4}-\mathrm{CNT}$ nanofluids exhibit non-Newtonian behavior (shear-thinning) in the whole range of the shear rate. The measured data show that for the $\mathrm{Fe}_{3} \mathrm{O}_{4}-\mathrm{CNT}$-water nanofluid, TMAH has more influence on the viscosity than other surfactants. The viscosity of $\mathrm{Fe}_{3} \mathrm{O}_{4}-\mathrm{CNT}$-water nanofluid is $44.2 \%$ and $49.9 \%$ higher than the base fluid at $0.5 \%$ and $1 \%$ volume fraction, respectively. In contrast, the $0.5 \%$ and $1 \%$ water-based $\mathrm{TSC}-\mathrm{Fe}_{3} \mathrm{O}_{4}-\mathrm{CNT}$ nanofluids show slight increases of $29.3 \%$ and $36 \%$ in the average viscosity, respectively.

$1 \mathrm{vol} \% \mathrm{Fe}_{3} \mathrm{O}_{4}$-water nanofluid with a ratio of nanoparticles to Colace (10:1) was mixed with the distilled water. Experimental values of the nanofluid viscosity are compared with results in other references (Wang et al. [16] and Kestin et al. [22]). Figure 10 presents a validation of the reliability of the present testing results. This figure presents an examination of the reliability of the present test results. In addition, the viscosity of $1 \%$ ( $\mathrm{vol} \%) \mathrm{Fe}_{3} \mathrm{O}_{4}$-water nanofluid decreases with the increase in temperature. The reason is that adhesion forces both between particles and between molecules are weakened due to the increase in temperature.

The viscosity and thermal conductivity of nanofluids are measured three times in every test, and the average values were taken as the final results. Figure 11 shows a repeatability investigation of experimental results. For the $\mathrm{Fe}_{3} \mathrm{O}_{4}-\mathrm{TMAH}$-water nanofluid, three test results of viscosity have good consistency. The data show that for the $0.5 \mathrm{vol} \% \mathrm{Fe}_{3} \mathrm{O}_{4}-\mathrm{TMAH}$-water nanofluid, the values of the thermal conductivity in three tests have little difference.

For the $\mathrm{Fe}_{3} \mathrm{O}_{4}$-water nanofluids with nanoparticle volume fractions of $1 \%$ and $0.5 \%$, the effect of various surfactants on the nanofluid viscosity is investigated with a constant ratio of nanoparticles to surfactants (10:1) as shown in Fig. 12. Compared with water-based PVP- $-\mathrm{Fe}_{3} \mathrm{O}_{4}$ and CTAB- $-\mathrm{Fe}_{3} \mathrm{O}_{4}$

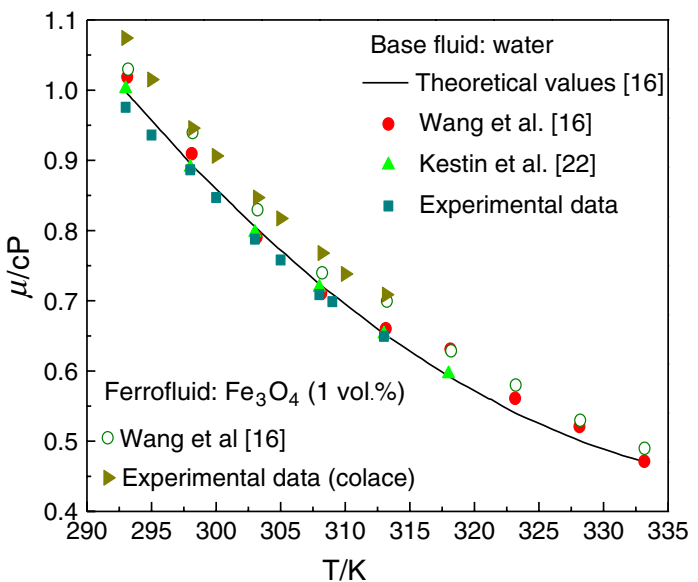

Fig. 10 Comparison between present viscosity values and data in Refs. $[16,22]$ at the shear rate of $73.38 \mathrm{~s}^{-1}$

nanofluids, the viscosity of $\mathrm{Fe}_{3} \mathrm{O}_{4}$-water nanofluids with Colace, TSC and TMAH increased slightly (on average below $12 \%$ ). However, compared with the average viscosity of water $(0.9634 \mathrm{cP})$, the average viscosities of the $0.5 \%$ and $1 \% \mathrm{Fe}_{3} \mathrm{O}_{4}$-water nanofluids with PVP increase by $91.6 \%$ and $163.6 \%$, respectively. The reason may be that the surfactant PVP with an additive mass ratio of 10:1 cannot effectively weaken the aggregation of the $\mathrm{Fe}_{3} \mathrm{O}_{4}$ nanoparticles.

Figure 13 investigates the effect of various surfactants on the viscosity of CNT-water nanofluid. After the SDBS is mixed into CNT-water nanofluids with nanoparticles $0.5 \%$ and $1 \%$ (vol\%), the viscosities of the CNT-water nanofluids increase by $167.5 \%$ and $290.8 \%$, respectively. Compared with other surfactants, the $0.5 \%$ and $1 \%$ CNT-water nanofluids with SDS show slight increases of the average viscosities by $5.4 \%$ and $9 \%$, respectively. It is considered that the nanofluid viscosity increases with the increase of the nanoparticle concentration. This is because nanoparticles show more interactions at high volume fraction, which increases the probability of the nanoparticle agglomeration.
Fig. 9 Viscosity of $\mathrm{Fe}_{3} \mathrm{O}_{4}-$ CNT-water nanofluids versus the shear rate at different surfactants

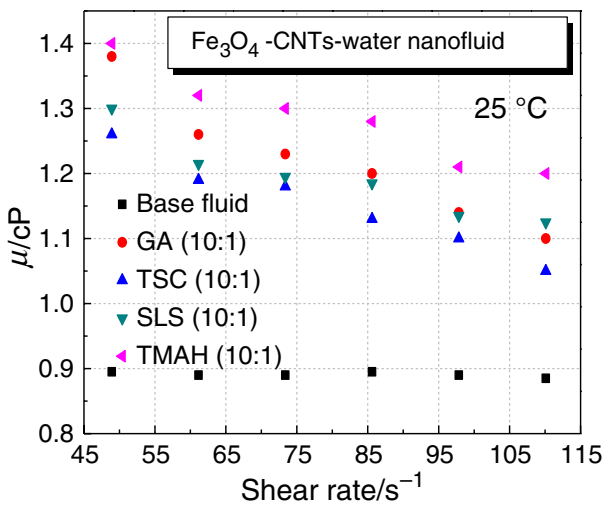

(a) $0.5 \%$ volume fraction

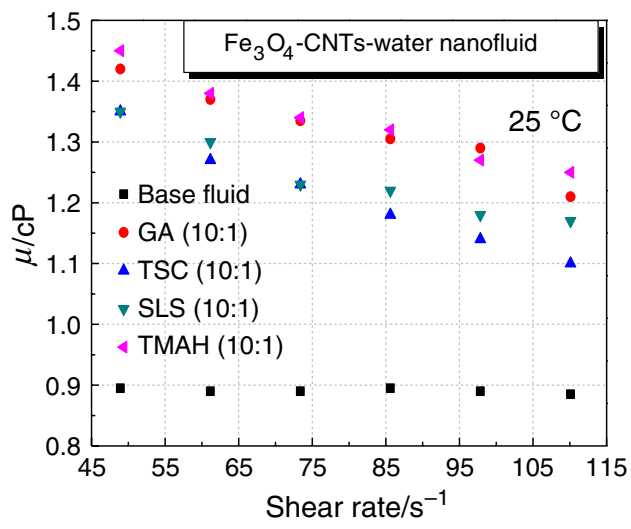

(b) $1 \%$ volume fraction 
Fig. 11 Repeatability validation of experimental results

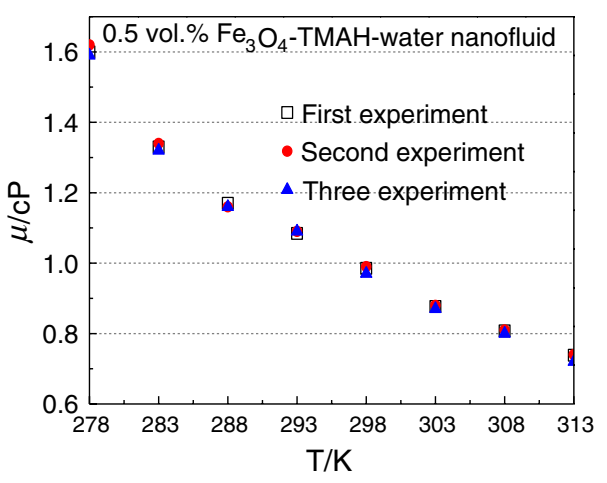

(a) Viscosity

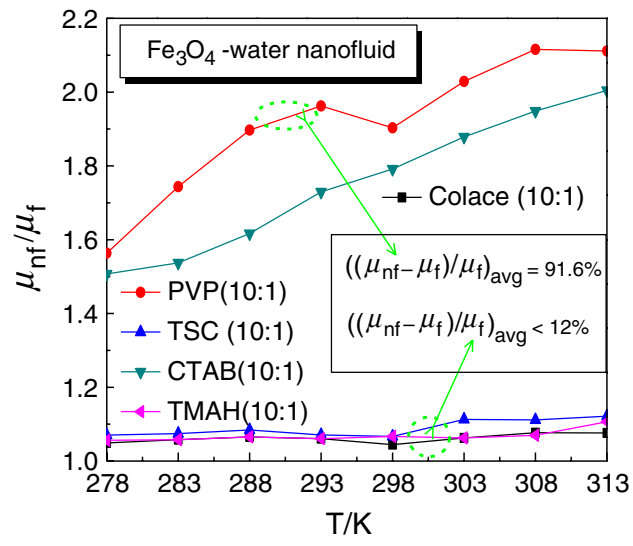

(a) $0.5 \%$ volume fraction

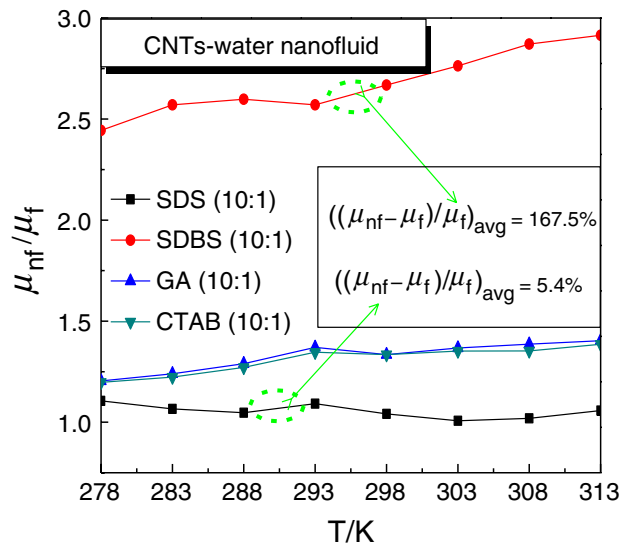

(a) $0.5 \%$ volume fraction

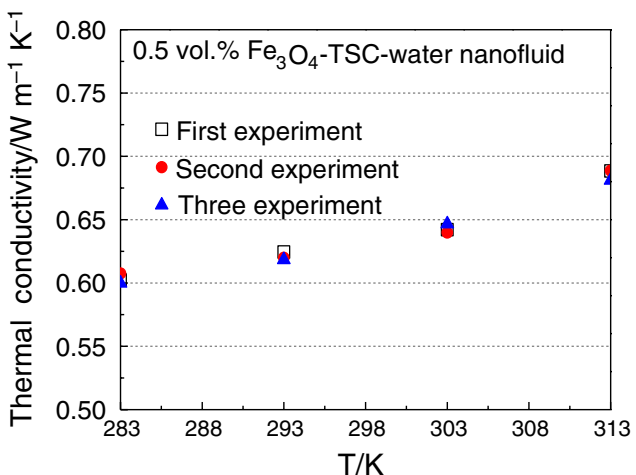

(b) Thermal conductivity

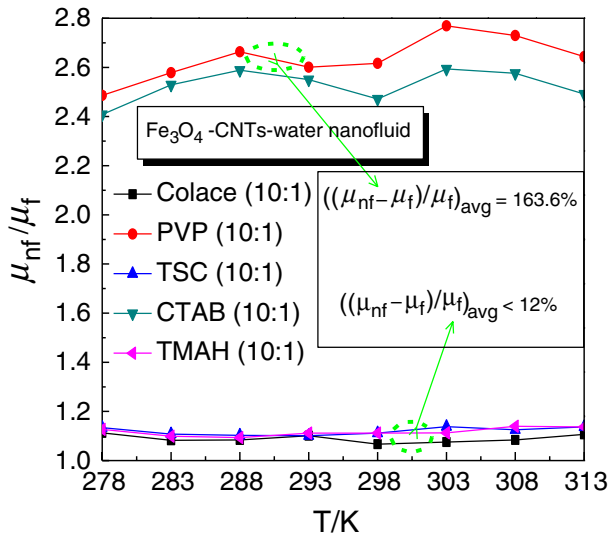

(b) $1 \%$ volume fraction

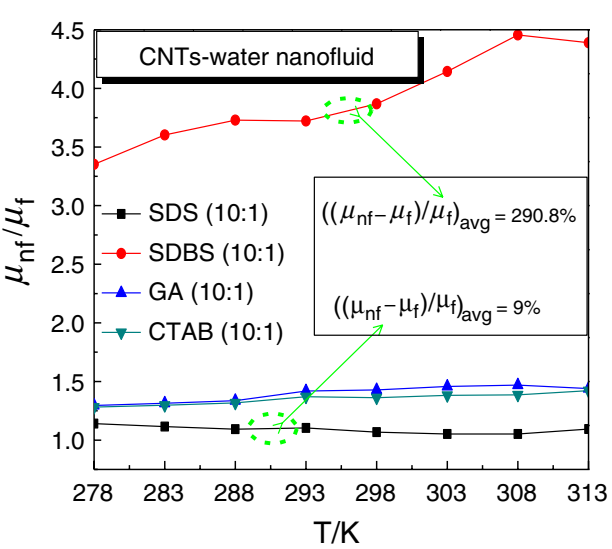

(b) $1 \%$ volume fraction
Fig. 13 Viscosities of CNTwater nanofluids for different surfactants at the shear rate of $73.38 \mathrm{~s}^{-1}$
These results, from Figs. 12 and 13, indicate that the Colace is recommended as the optimal surfactant for the reduction of the viscosity of the $\mathrm{Fe}_{3} \mathrm{O}_{4}$-water nanofluid, whereas the sodium dodecyl sulfate (SDS) is recommended for the CNT-water nanofluids.

Usually, CNTs show a higher thermal conductivity than $\mathrm{Fe}_{3} \mathrm{O}_{4}$ nanoparticles, whereas $\mathrm{Fe}_{3} \mathrm{O}_{4}$ nanoparticles under a magnetic field will enhance the heat transfer of the nanofluid. However, the viscosity of the nanofluid will increase to a certain extent due to the addition of both the nanoparticles and the surfactant into the water. According to a ratio of 3:1 $\left(\mathrm{Fe}_{3} \mathrm{O}_{4} / \mathrm{CNTs}\right)$, the nanofluid with hybrid nanoparticles is used to investigate the effect of various surfactants on the nanofluid viscosity as shown in Fig. 14. The measured data 
Fig. 14 Viscosities of $\mathrm{Fe}_{3} \mathrm{O}_{4}-$ CNT-water nanofluids for different surfactants at the shear rate of $73.38 \mathrm{~s}^{-1}$

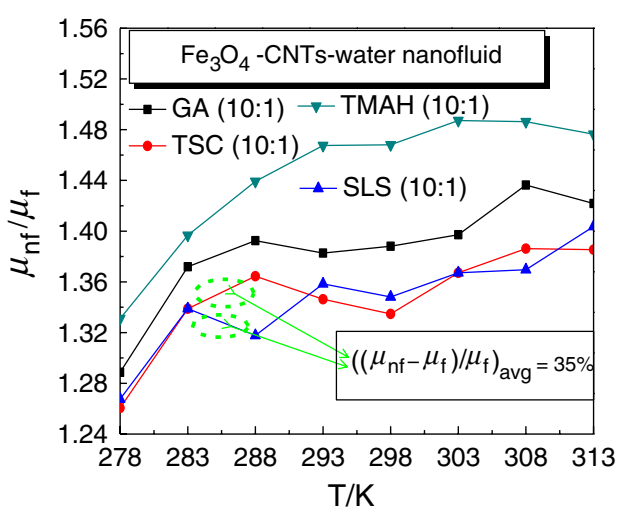

(a) $0.5 \%$ volume fraction

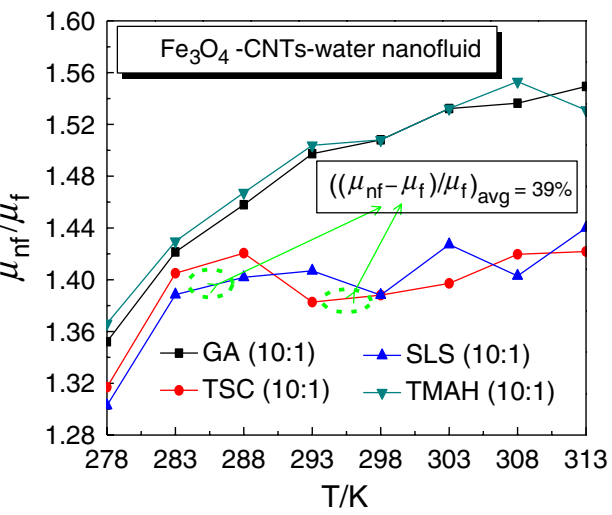

(b) $1 \%$ volume fraction show that the surfactants SLS and TSC result in about $39 \%$ increase in the average viscosity for $1 \% \mathrm{Fe}_{3} \mathrm{O}_{4}-\mathrm{CNT}$-water nanofluids, whereas about $35 \%$ increase occurs for $0.5 \%$ nanofluids.

Figure 15 exhibits a comparison of additive mass ratios (nanoparticles to surfactant) for $\mathrm{CNT}$-water and $\mathrm{Fe}_{3} \mathrm{O}_{4}-\mathrm{CNT}$-water nanofluids. It may be seen that for all the nanofluids more surfactant results in higher viscosity. Furthermore, the CNT-water nanofluid with the additive mass ratio of 5:1 shows a similar viscosity variation to that with the ratio $10: 1$. Compared with the ratio of $10: 1$, the viscosities of the SDS-CNTs and GA-CNTs nanofluids with additive mass ratio of 2:1 significantly increase by $57.2 \%$ and $54.6 \%$, respectively. For the hybrid nanofluid with the nanoparticles $\mathrm{Fe}_{3} \mathrm{O}_{4}$ and CNTs, the surfactant SLS with an additive mass ratio of 10:1 improves the best separation of hybrid particles to prevent nanoparticle settling and clumping.

\section{Stability of nanofluid}

A nanofluid can maintain a uniform suspension state for a long time, which means a good stability. Zeta potential and sedimentation methods are used to evaluate the stability of nanofluids. For the nanofluid that can be used in industrial applications, the primary concern is its longterm stability. The addition of surfactant is considered to be the simplest and most economic method to improve the stability of nanofluids [23]. Several types of surfactants were utilized in $\mathrm{Fe}_{3} \mathrm{O}_{4}$-water nanofluid, and it is found that researchers recommended TSC in Ref. [24], CTAB in Ref. [25] and TMAH in Ref. [26]. For the CNT-water nanofluid, GA in Ref. [27], SDBS in Ref. [28], CTAB in Ref. [29], and SDS in Ref. [30] were used as surfactants for dispersion of nanoparticles in the base fluid. The surfactants GA and SLS were used in the $\mathrm{Fe}_{3} \mathrm{O}_{4}-\mathrm{CNT}$-water nanofluid. However, thermophysical properties of the nanofluid are significantly affected by the surfactant, the surfactants selected in this study are based on previous work. Figure 16 presents photos of the CNT-SDS-water nanofluid after different static duration, i.e., after $5 \mathrm{~min}$, 1 week, and 2 weeks. Through processes of the stirring and shaking, the nanofluid shows a large amount of foam. It is found that the prepared nanofluid is sufficiently stable after 2 weeks. Figure 17 illustrates the prepared $\mathrm{Fe}_{3} \mathrm{O}_{4}-\mathrm{CNT}$-water nanofluid after standing $5 \mathrm{~min}$ and
Fig. 15 Nanofluid viscosities with different surfactants and various additive mass ratios (nanoparticles to surfactant) at the shear rate of $73.38 \mathrm{~s}^{-1}$

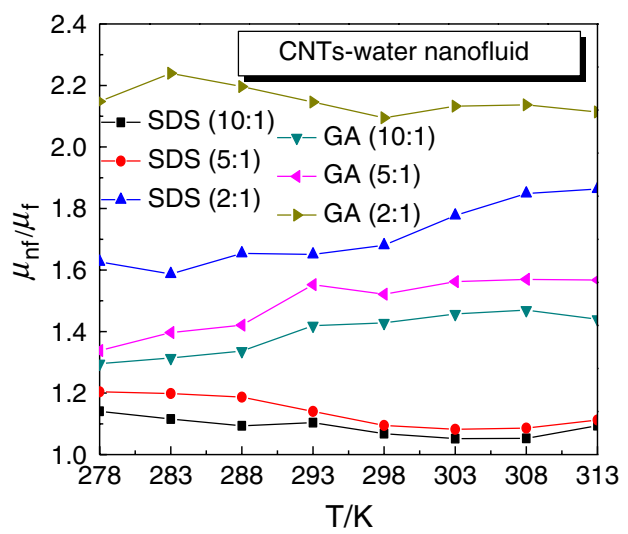

(a) $1 \%$ CNTs-water nanofluid

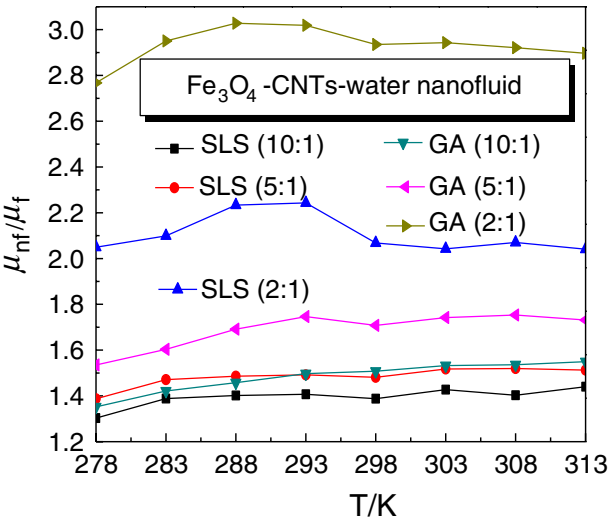

(b) $1 \% \mathrm{Fe}_{3} \mathrm{O}_{4}$-CNTs-water nanofluid 


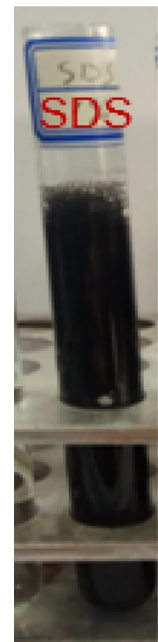

(a) Afte $5 \mathrm{~min}$

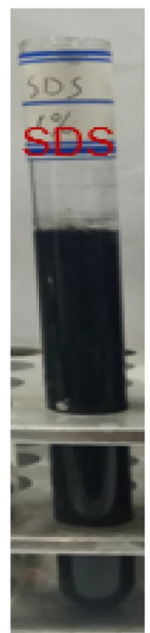

(b) After one week

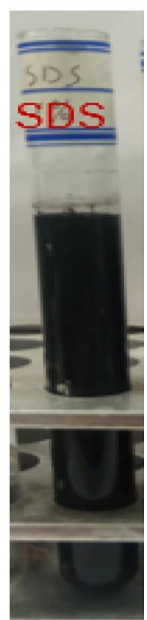

(c) After two weeks
Fig. 16 Photographs of 1 vol\% CNT-water nanofluid

2 weeks. The $\mathrm{Fe}_{3} \mathrm{O}_{4}-\mathrm{CNT}$-water nanofluids with various surfactants (GA, TMAH, TSC and SLS) are stable after 2 weeks.

Measurements of zeta potential for a nanofluid provide an evaluation of nanofluid stability. A well-stabilized nanofluid has a zeta potential value (absolute value) of higher than $30 \mathrm{mV}$ as shown in Ref. [31]. The stabilities of the water-based $\mathrm{Fe}_{3} \mathrm{O}_{4}-\mathrm{TMAH}, \mathrm{Fe}_{3} \mathrm{O}_{4}$-Colace, $\mathrm{Fe}_{3} \mathrm{O}_{4}-\mathrm{TSC}$, CNT-SDS, CNT-GA, $\mathrm{Fe}_{3} \mathrm{O}_{4}-\mathrm{CNT}-\mathrm{SLS}$, and $\mathrm{Fe}_{3} \mathrm{O}_{4}-\mathrm{CNT}-\mathrm{TSC}$ nanofluids with a volume concentration of $0.5 \%$ were investigated by testing the nanofluid viscosity. The zeta potential of the nanofluid was measured using the ZS-90 zeta potential analyzer (Malvern Panalytical, Britain). Figure 18 presents zeta potential distribution of 0.5 vol $\% \mathrm{Fe}_{3} \mathrm{O}_{4}-\mathrm{TMAH}-$ water nanofluid. The zeta potential

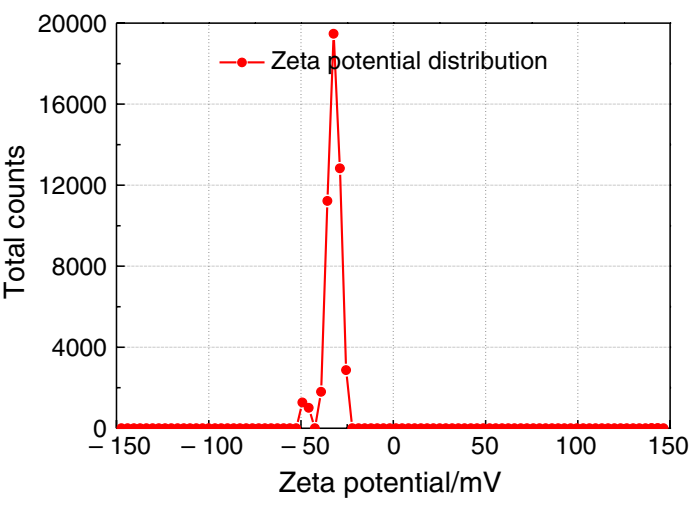

Fig. 18 Zeta potential distribution of $\mathrm{Fe}_{3} \mathrm{O}_{4}-\mathrm{TMAH}-$ water nanofluid

of the water-based $\mathrm{Fe}_{3} \mathrm{O}_{4}-\mathrm{TMAH}$ nanofluid is $-32.8 \mathrm{mV}$. Figure 19 displays measured absolute values of the zeta potential for seven nanofluids. For the $\mathrm{Fe}_{3} \mathrm{O}_{4}$-water nanofluid, the highest value of the zeta potential $(36.8 \mathrm{mV})$ is attained by using the surfactant TSC. However, the waterbased $\mathrm{Fe}_{3} \mathrm{O}_{4}$-Colace nanofluid shows a zeta potential value of $17.2 \mathrm{mV}(<30 \mathrm{mV})$. With a volume concentration of $0.5 \%$, the zeta potentials of the water-based CNT-SDS, CNT-GA, $\mathrm{Fe}_{3} \mathrm{O}_{4}-\mathrm{CNT}-\mathrm{SLS}$ and $\mathrm{Fe}_{3} \mathrm{O}_{4}-\mathrm{CNT}-\mathrm{TSC}$ nanofluids are $36.6 \mathrm{mV}, 30.2 \mathrm{mV}, 35.8 \mathrm{mV}$, and $27.8 \mathrm{mV}$, respectively. These results indicate that $\mathrm{Fe}_{3} \mathrm{O}_{4}-\mathrm{TSC}, \mathrm{CNT}-\mathrm{SDS}$ and $\mathrm{Fe}_{3} \mathrm{O}_{4}-\mathrm{CNT}-\mathrm{SLS}$ water-based nanofluids have the excellent dispersion stability.

\section{Thermal conductivity of nanofluid}

In the present study, experimental values of thermal conductivity of DI water are compared with results in Refs. [25] and
Fig. 17 Photographs of 1 vol\% $\mathrm{Fe}_{3} \mathrm{O}_{4}-\mathrm{CNT}$-water nanofluid with various surfactants

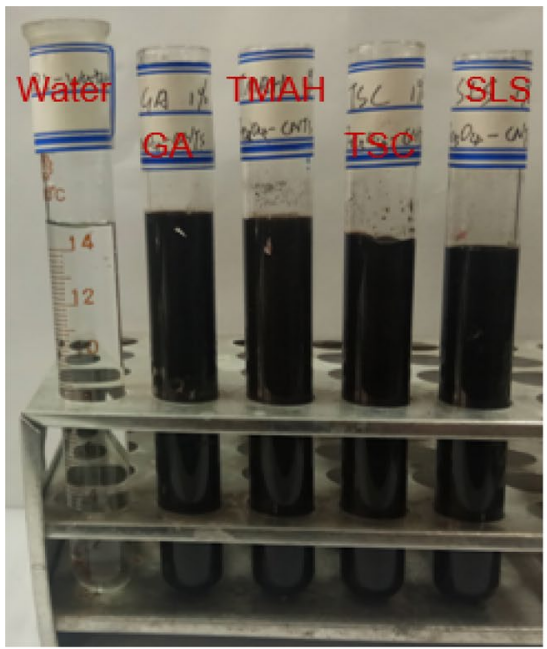

(a) After 5 min from preparation

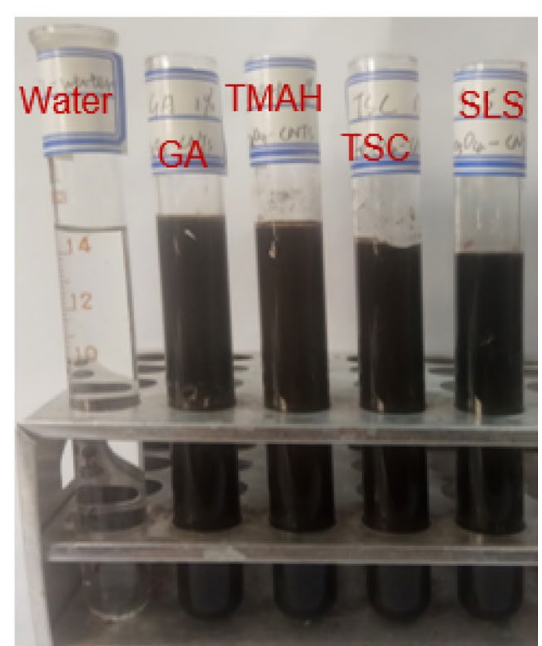

(b) After two weeks from preparation 


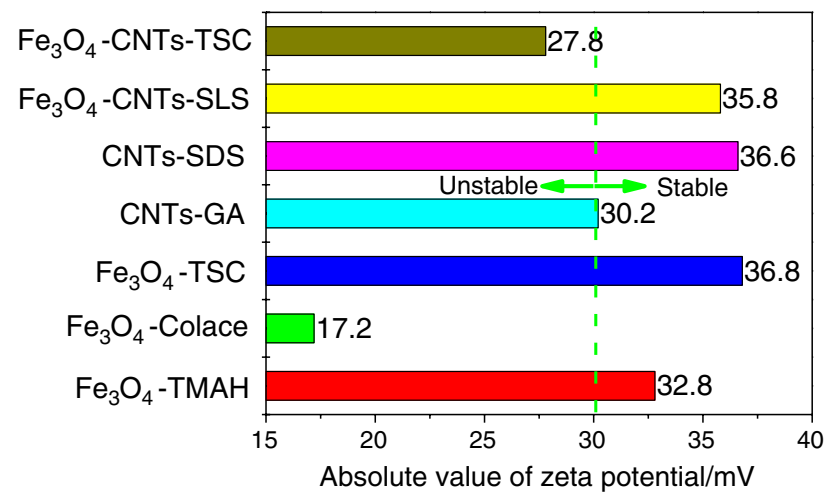

Fig. 19 Zeta potential of water-based 0.5 vol\% nanofluids

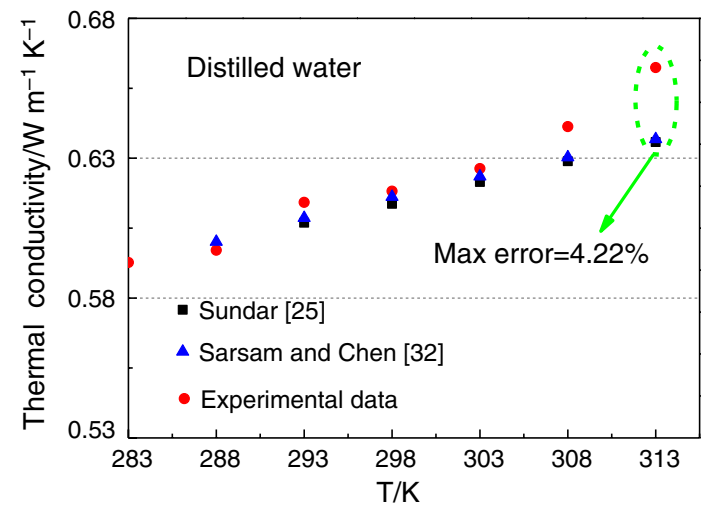

Fig. 20 Comparison between tested values of thermal conductivity and data in Refs. [25, 32]

[32]. A maximum deviation of $4.22 \%$ is observed as shown in Fig. 20.

Thermal conductivities of various nanofluids were measured in the temperature range of $10-40{ }^{\circ} \mathrm{C}$ using DRE-2B thermal property analyzer. Thermal conductivities of $\mathrm{Fe}_{3} \mathrm{O}_{4}-\mathrm{TMAH}, \mathrm{Fe}_{3} \mathrm{O}_{4}$-Colace, $\mathrm{Fe}_{3} \mathrm{O}_{4}-\mathrm{TSC}$, CNT-SDS, CNT-GA, $\mathrm{Fe}_{3} \mathrm{O}_{4}-\mathrm{CNT}-\mathrm{SLS}$, and $\mathrm{Fe}_{3} \mathrm{O}_{4}-\mathrm{CNT}-\mathrm{TSC}$ nanofluids with volume concentration of $0.5 \%$ are measured as shown in Fig. 21. The thermal conductivities of seven nanofluids increase with increasing temperature. Compared with the base fluid, thermal conductivity enhancements of $3.47-5.43 \%, 1.47-4.21 \%$ and $2.48-4.72 \%$ are observed for $\mathrm{Fe}_{3} \mathrm{O}_{4}-\mathrm{TMAH}, \mathrm{Fe}_{3} \mathrm{O}_{4}$-Colace, and $\mathrm{Fe}_{3} \mathrm{O}_{4}-\mathrm{TSC}$ nanofluids, respectively. Compared with the $\mathrm{TSC}-\mathrm{Fe}_{3} \mathrm{O}_{4}$ and Colace- $\mathrm{Fe}_{3} \mathrm{O}_{4}$ nanofluids, the TMAH- $\mathrm{Fe}_{3} \mathrm{O}_{4}$ nanofluid has a higher thermal conductivity. The measured data show that compared with the base fluid, the water-based CNT-SDS, CNT-GA, $\mathrm{Fe}_{3} \mathrm{O}_{4}-\mathrm{CNT}-\mathrm{SLS}$, and $\mathrm{Fe}_{3} \mathrm{O}_{4}-\mathrm{CNT}-\mathrm{TSC}$ nanofluids show the average enhancements of the thermal conductivities of $8.23 \%, 7.54 \%, 5.78 \%$, and $4.87 \%$, respectively. The results reveal that the surfactant SDS is recommended for the enhancement of the thermal conductivity of the

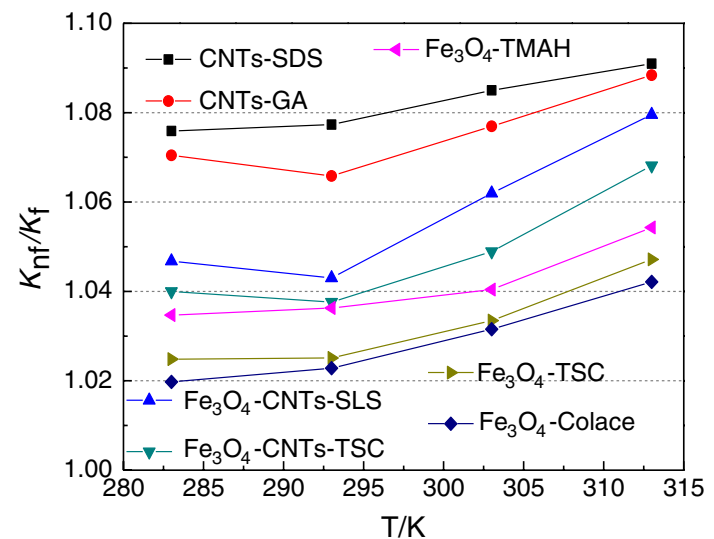

Fig. 21 Thermal conductively of 0.5 vol\% water-based nanofluids with various surfactants

CNT-water nanofluid, whereas the surfactant SLS is recommended for the $\mathrm{Fe}_{3} \mathrm{O}_{4}-\mathrm{CNT}$-water nanofluids.

\section{Fitting of empirical formulas}

It was observed that nanofluids exhibited both non-Newtonian and Newtonian behavior. The viscosity of a Newtonian fluid depends on the shear rate, whereas the non-Newtonian fluid shows a completely different rheological behavior $[11$, 13, 17].

Generally, the viscosity of a Newtonian fluid at a low volume concentration of solid nanoparticles $(\varphi<2 \%)$ can be predicted by using the Einstein equation [33]. This equation is given by:

$\mu_{\mathrm{nf}}=\mu_{\mathrm{f}}(1+2.5 \varphi)$

where $\varphi$ is the volume fraction of the nanoparticles. $\mu_{\mathrm{nf}}$ and $\mu_{\mathrm{f}}$ represent viscosities of the nanofluid and the base fluid, respectively. Batchelor [34] modified Einstein's viscosity equation by considering the effect of Brownian motion of the nanoparticles, and the modified formula was given as follows

$\mu_{\mathrm{nf}}=\mu_{\mathrm{f}}\left(1+2.5 \varphi+6.2 \varphi^{2}\right)$

For a suspension with moderate solid volume fraction (below 4\%), the viscosity was reported by Brinkman [35] as

$\mu_{\mathrm{nf}}=\mu_{\mathrm{f}}(1-\varphi)^{-2.5}$

Sundar et al. [25] proposed an improved theoretical equation to predict the viscosity of magnetic nanofluids:

$\mu_{\mathrm{nf}}=\mu_{\mathrm{f}}(1+\varphi / 12.5)^{6.356}$

Based on the present experimental results, empirical correlations at a low volume concentration of nanoparticles 
$(\varphi \leq 1 \%)$ are improved by considering the viscosity as a function of the nanofluid temperature, volume fraction of nanoparticles and surfactant. With various surfactants, the viscosity of the $\mathrm{Fe}_{3} \mathrm{O}_{4}$-water nanofluid is fitted using Eqs. (7)-(9) as follows:

$\mu_{\mathrm{nf}}=(A \varphi+1.065) 590.53 e^{-0.022 \mathrm{~T}}$

$\mu_{\mathrm{nf}}=\left(190000 \theta^{2}-380 \theta+1.239\right)(A \varphi+1.065) 590.53 e^{-0.022 \mathrm{~T}}$

$\mu_{\mathrm{nf}}=\left(10357.6 \theta^{2}-27.806 \theta+1.0181\right)(A \varphi+1.065) 590.53 e^{-0.022 \mathrm{~T}}$

where $\theta$ is the ratio fraction of the surfactant, and $\varphi$ is the volume fraction of the nanoparticles as in other equations above. The mass ratio of surfactant to nanoparticles is equal to $100 \theta$. For the $\mathrm{Fe}_{3} \mathrm{O}_{4}$-water nanofluid, the constant $A$ depends on species and volume fraction of surfactants as given in Table 2. For the $\mathrm{Fe}_{3} \mathrm{O}_{4}$-water nanofluids with most surfactants (Colace, PVP, TSC, CTAB and TMAH), Eq. (7) shows an average deviation of less than $4 \%$. Moreover, for the $\mathrm{Fe}_{3} \mathrm{O}_{4}$ nanofluids with different fractions $(\theta=0.1-0.5 \%)$ of the surfactants Colace and TSC, Eqs. (8) and (9) provide average deviations of $4.40 \%$ and $2.44 \%$, respectively.

For the CNT-water nanofluid with $0.1 \%$ surfactants (SDBS, GA, CTAB and SDS), the viscosity of the nanofluid can be predicted by Eqs. (10)-(13):

$\mu_{\mathrm{nf}}=\left(-6160.7 \varphi^{2}+B \varphi+1.065\right) 590.53 e^{-0.022 \mathrm{~T}}$

$$
\begin{aligned}
\mu_{\mathrm{nf}}= & (10.5 \varphi+1.065) 590.53 e^{-0.022 \mathrm{~T}} \\
\mu_{\mathrm{nf}}= & \left(11800 \theta^{2}+58 \theta+0.93\right)(10.5 \varphi+1.065) 590.53 e^{-0.022 \mathrm{~T}} \\
\mu_{\mathrm{nf}}= & \left(11800 \theta^{2}+60 \theta+0.93\right)\left(-6160.7 \varphi^{2}+B \varphi+1.065\right) \\
& 590.53 e^{-0.022 \mathrm{~T}}
\end{aligned}
$$

where the constant $B$ depends on species and volume fraction of surfactants which were added into the CNT-water nanofluid. An average deviation of less than $4 \%$ is found in most equations for the CNT-water nanofluid with $\theta=0.1 \%$ and $\varphi \leq 1 \%$. However, when the effect of the ratio fraction of the surfactant is investigated using $\theta=0.1-0.5 \%$, Eq. (12) shows an average deviation of $4.28 \%$.

$\mathrm{Fe}_{3} \mathrm{O}_{4}$-CNT-water nanofluid is synthesized using nanoparticles $\mathrm{Fe}_{3} \mathrm{O}_{4}$ and CNTs with a ratio of 3:1 into the distilled water. Based on the measurements, three empirical correlations are proposed as follows:

$\mu_{\mathrm{nf}}=\left(-6199.4 \varphi^{2}+C \varphi+1.065\right) 590.53 e^{-0.022 \mathrm{~T}}$

$\mu_{\mathrm{nf}}=\left(30000 \theta^{2}-30 \theta+1\right)\left(-6199.4 \varphi^{2}+C \varphi+1.065\right) 590.53 e^{-0.022 \mathrm{~T}}$

$\mu_{\mathrm{nf}}=\left(19667 \theta^{2}+100 \theta+0.9033\right)\left(-6199.4 \varphi^{2}+C \varphi+1.065\right)$ $590.53 e^{-0.022 \mathrm{~T}}$
Table 2 Information of empirical formulas (vol\%)

\begin{tabular}{lllllll}
\hline Nanoparticle & Surfactant & $\theta / \%$ & $\varphi / \%$ & Parameters & $\begin{array}{l}\text { Average } \\
\text { deviation/\% }\end{array}$ & Equations \\
\hline $\mathrm{Fe}_{3} \mathrm{O}_{4}$ & Colace & 0.1 & $0-1$ & $A=7.6645$ & 1.99 & Equation (7) \\
$\mathrm{Fe}_{3} \mathrm{O}_{4}$ & PVP & 0.1 & $0-1$ & $A=175$ & 4.44 & Equation (7) \\
$\mathrm{Fe}_{3} \mathrm{O}_{4}$ & TSC & 0.1 & $0-1$ & $A=12.5$ & 2.44 & Equation (7) \\
$\mathrm{Fe}_{3} \mathrm{O}_{4}$ & CTAB & 0.1 & $0-1$ & $A=155$ & 4.36 & Equation (7) \\
$\mathrm{Fe}_{3} \mathrm{O}_{4}$ & TMAH & 0.1 & $0-1$ & $A=11.776$ & 2.29 & Equation (7) \\
$\mathrm{Fe}_{3} \mathrm{O}_{4}$ & Colace & $0.1-0.5$ & 1 & $A=7.6645$ & 4.40 & Equation (8) \\
$\mathrm{Fe}_{3} \mathrm{O}_{4}$ & TSC & $0.1-0.5$ & 1 & $A=12.5$ & 2.44 & Equation (9) \\
$\mathrm{CNTs}$ & SDBS & 0.1 & $0-1$ & $B=349.63$ & 3.86 & Equation (10) \\
$\mathrm{CNTs}$ & GA & 0.1 & $0-1$ & $B=102$ & 3.74 & Equation (10) \\
$\mathrm{CNTs}$ & CTAB & 0.1 & $0-1$ & $B=98.68$ & 3.19 & Equation (10) \\
$\mathrm{CNTs}$ & SDS & 0.1 & $0-1$ & - & 3.08 & Equation (11) \\
$\mathrm{CNTs}$ & SDS & $0.1-0.5$ & 1 & - & 4.28 & Equation (12) \\
$\mathrm{CNTs}_{\mathrm{Fe}_{3} \mathrm{O}_{4}-\mathrm{CNTs}}$ & GA & $0.1-0.5$ & 1 & $B=102$ & 3.73 & Equation (13) \\
$\mathrm{Fe}_{3} \mathrm{O}_{4}-\mathrm{CNTs}$ & SLS & 0.1 & $0-1$ & $C=112$ & 2.85 & Equation (14) \\
$\mathrm{Fe}_{3} \mathrm{O}_{4}-\mathrm{CNTs}$ & TSC & 0.1 & $0-1$ & $C=102$ & 2.13 & Equation (14) \\
$\mathrm{Fe}_{3} \mathrm{O}_{4}-\mathrm{CNTs}$ & TMAH & 0.1 & $0-1$ & $C=100$ & 1.93 & Equation (14) \\
$\mathrm{Fe}_{3} \mathrm{O}_{4}-\mathrm{CNTs}$ & SLS & $0.1-0.5$ & 1 & $C=102$ & 2.73 & Equation (14) \\
$\mathrm{Fe}_{3} \mathrm{O}_{4}-\mathrm{CNTs}$ & GA & $0.1-0.5$ & 1 & $C=112$ & 3.50 & Equation (15) \\
\hline & & & & & & Equation (16) \\
& & $0-1$ & $C=113$ & 3.13 &
\end{tabular}


Table 3 Thermal conductivity of empirical formulas

\begin{tabular}{lllllll}
\hline Nanoparticle & Surfactant & $A$ & $B$ & $C$ & $R^{2}$ & Equations \\
\hline $\mathrm{Fe}_{3} \mathrm{O}_{4}$ & Colace & $2 \times 10^{-5}$ & 0.0104 & 2.4678 & 0.9976 & Equation (17) \\
$\mathrm{Fe}_{3} \mathrm{O}_{4}$ & TSC & $3 \times 10^{-5}$ & 0.0192 & 3.7801 & 0.9988 & Equation (17) \\
$\mathrm{Fe}_{3} \mathrm{O}_{4}$ & TMAH & $3 \times 10^{-5}$ & 0.0178 & 3.5898 & 0.9891 & Equation (17) \\
$\mathrm{CNTs}$ & GA & $4 \times 10^{-5}$ & 0.0233 & 4.4431 & 0.9587 & Equation (17) \\
$\mathrm{CNTs}$ & SDS & $1 \times 10^{-5}$ & 0.0063 & 1.9347 & 0.9788 & Equation (17) \\
$\mathrm{Fe}_{3} \mathrm{O}_{4}-\mathrm{CNTs}$ & SLS & $5 \times 10^{-5}$ & 0.0307 & 5.4471 & 0.9650 & Equation (17) \\
$\mathrm{Fe}_{3} \mathrm{O}_{4}-\mathrm{CNTs}$ & TSC & $5 \times 10^{-5}$ & 0.0312 & 5.5548 & 0.9970 & Equation (17) \\
\hline
\end{tabular}

These equations provide a description of the dependence of the $\mathrm{Fe}_{3} \mathrm{O}_{4}-\mathrm{CNT}$-water nanofluid viscosity on temperature, particle volume fractions, and surfactant species. Compared with the equations for the $\mathrm{Fe}_{3} \mathrm{O}_{4}$-water and CNT-water nanofluids, Eqs. (14)-(16) show a lower average deviation for the nanofluid with hybrid nanoparticles, and the maximum value of the deviation is $3.50 \%$ at $\theta=0.1-0.5 \%$ and $\varphi \leq 1 \%$.

For the $\mathrm{Fe}_{3} \mathrm{O}_{4}$-water, $\mathrm{CNT}$-water and $\mathrm{Fe}_{3} \mathrm{O}_{4}-\mathrm{CNT}$-water nanofluids, empirical correlations based on experimental values at $\varphi=0.5 \%$ are proposed by considering the thermal conductivity as a function of the nanofluid temperature (283-313 K). The thermal conductivity of the nanofluid can be predicted by Eq. (17):

$\frac{k_{\mathrm{nf}}}{k_{\mathrm{f}}}(T)=A T^{2}-B T+C$

More information of empirical formula is shown in Table 3. These empirical formulas show a minimum goodness of fit $\left(R^{2}\right)$ of $95.87 \%$, and the maximum deviation is $4.13 \%$ compared to the reference value in the ASHRAE Handbook 2005.

\section{Conclusions}

This study provides important information on $\mathrm{Fe}_{3} \mathrm{O}_{4}$ nanoparticles and carbon nanotubes in deionized water. The viscosity of these nanofluids is affected by nanoparticle size, volume fraction, and temperature. In addition, this paper investigates an effect of various surfactants, including acacia senegal (GA), trisodium citrate dihydrate (TSC), sodium laurylsulfonate (SLS), tetramethylammonium hydroxide (TMAH), sodium dodecyl sulfate (SDS), cetyl trimethylammonium bromide (CTAB), and sodium dodecyl benzene sulfonate (SDBS). Stability, viscosity and thermal conductivity of various nanofluids $\left(\mathrm{Fe}_{3} \mathrm{O}_{4}-\mathrm{TMAH}, \mathrm{Fe}_{3} \mathrm{O}_{4}\right.$-Colace, $\mathrm{Fe}_{3} \mathrm{O}_{4}-\mathrm{TSC}$, CNT-SDS, CNT-GA, $\mathrm{Fe}_{3} \mathrm{O}_{4}-\mathrm{CNT}-\mathrm{SLS}$ and $\mathrm{Fe}_{3} \mathrm{O}_{4}-\mathrm{CNT}-\mathrm{TSC}$ nanofluids) are tested with a volume fraction of $0.5 \%$. The major conclusions of this research are attained as follows:

1. In the whole range of shear rate, rheological behaviors of non-Newtonian (shear-thinning) are observed for various $\mathrm{Fe}_{3} \mathrm{O}_{4}-\mathrm{CNTs}$ nanofluids $\left(\mathrm{GA}-\mathrm{Fe}_{3} \mathrm{O}_{4}-\mathrm{CNTs}\right.$, TSC- $\mathrm{Fe}_{3} \mathrm{O}_{4}-\mathrm{CNTs}$, SLS- $\mathrm{Fe}_{3} \mathrm{O}_{4}-\mathrm{CNTs}$ and TMAH$\mathrm{Fe}_{3} \mathrm{O}_{4}-\mathrm{CNTs}$ nanofluids) and various CNTs nanofluids (SDS-CNTs, CTAB-CNTs, SDBS-CNTs and GACNTs nanofluids). However, the rheological behaviors of water-based docusate sodium- $\mathrm{Fe}_{3} \mathrm{O}_{4}$, tetramethylammonium hydroxide- $-\mathrm{Fe}_{3} \mathrm{O}_{4}$ and trisodium citrate dihydrate- $\mathrm{Fe}_{3} \mathrm{O}_{4}$ nanofluids are almost Newtonian in the whole range of the shear rate.

2. Due to good stability, high thermal conductivity and low viscosity, the surfactants TMAH, SDS, and SLS are recommended for the water-based $\mathrm{Fe}_{3} \mathrm{O}_{4}, \mathrm{CNT}$, and $\mathrm{Fe}_{3} \mathrm{O}_{4}-\mathrm{CNT}$-nanofluids, respectively.

3. For $\mathrm{Fe}_{3} \mathrm{O}_{4}-\mathrm{CNT}$-water nanofluids, some empirical formulas with a maximum deviation of $3.50 \%$ are proposed to predict the nanofluid viscosity accurately. These empirical formulas provide an essential reference for future numerical research.

Acknowledgements Open access funding provided by Lund University. The authors gratefully acknowledge the supports of the National Natural Science Foundations of China (Grant No. 51576059) and Foundation of Key Laboratory of Thermo-Fluid Science and Engineering (Xi' an Jiaotong University), Ministry of Education, Xi' an 710049, P.R. China (Grant No. KLTFSE2018KFJJ01).

Open Access This article is licensed under a Creative Commons Attribution 4.0 International License, which permits use, sharing, adaptation, distribution and reproduction in any medium or format, as long as you give appropriate credit to the original author(s) and the source, provide a link to the Creative Commons licence, and indicate if changes were made. The images or other third party material in this article are included in the article's Creative Commons licence, unless indicated otherwise in a credit line to the material. If material is not included in the article's Creative Commons licence and your intended use is not permitted by statutory regulation or exceeds the permitted use, you will need to obtain permission directly from the copyright holder. To view a copy of this licence, visit http://creativecommons.org/licenses/by/4.0/. 


\section{Appendix 1: Uncertainty analysis}

The accuracy for the temperature measurement is $0.1{ }^{\circ} \mathrm{C}$ between 5 and $40{ }^{\circ} \mathrm{C}$. The maximum $\frac{\delta T}{T}$ is equal to 0.02 . Accuracy of the viscometer is $\pm 1.0 \%$. The maximum uncertainty of the viscosity $\left(U_{\mu}\right)$ is determined by:

$U \mu=\sqrt{\left(\frac{\delta T}{T}\right)^{2}+\left(\frac{\delta \mu_{\mathrm{nf}}}{\mu_{\mathrm{nf}}}\right)^{2}}=\sqrt{(0.02)^{2}+(0.01)^{2}}=2.24 \%$

where the maximum uncertainty of the viscosity is $2.24 \%$.

Accuracy of the thermal property analyzer is $\pm 3.0 \%$. The accuracy for temperature measurement is $0.1^{\circ} \mathrm{C}$ between 10 and $40{ }^{\circ} \mathrm{C}$. Therefore, the maximum $\frac{\delta T}{T}$ will be equal 0.01 . The maximum uncertainty of the thermal conductivity $\left(U_{\kappa}\right)$ is determined by:

$U_{k}=\sqrt{\left(\frac{\delta T}{T}\right)^{2}+\left(\frac{\delta k_{\mathrm{nf}}}{k_{\mathrm{nf}}}\right)^{2}}=\sqrt{(0.01)^{2}+(0.03)^{2}}=3.16 \%$

So the maximum uncertainty of the thermal conductivity is $3.16 \%$.

\section{References}

1. Mahendran V, Philip J. Nanofluid based optical sensor for rapid visual inspection of defects in ferromagnetic materials. Appl Phys Lett. 2012;100:073104-1-3.

2. Mahendran V, Philip J. An optical technique for fast and ultrasensitive detection of ammonia using magnetic nanofluids. Appl Phys Lett. 2013;102:063107-1-4.

3. Rashidi S, Mahian O, Languri EM. Applications of nanofluids in condensing and evaporating systems. J Therm Anal Calorim. 2018;131:2027-39.

4. Rashidi S, Karimi N, Mahian O, Esfahani JA. A concise review on the role of nanoparticles upon the productivity of solar desalination systems. J Therm Anal Calorim. 2019;135:1145-59.

5. Sundar LS, Singh MK, Sousa ACM. Enhanced heat transfer and friction factor of MWCNT- $\mathrm{Fe}_{3} \mathrm{O}_{4} /$ water hybrid nanofluids. Int Commun Heat Mass Transf. 2014;52:73-83.

6. Yarmand H, Gharehkhani S, Ahmadi G, Shirazi SFS, Baradaran S, Montazer E, Zubir MNM, Alehashem MS, Kazi SN, Dahari M. Graphene nanoplatelets-silver hybrid nanofluids for enhanced heat transfer. Energ Convers Manage. 2015;100:419-28.

7. Chen Z, Zheng D, Wang J, Chen L, Sundén B. Experimental investigation on heat transfer characteristics of various nanofluids in an indoor electric heater. Renew Energy. 2020;147:1011-8.

8. Izadkhah MS, Erfan-Niya H, Heris SZ. Influence of graphene oxide nanosheets on the stability and thermal conductivity of nanofluids. J Therm Anal Calorim. 2019;135:581-95.

9. Ranjbarzadeh R, Moradikazerouni A, Bakhtiari R, Asadi A, Afrand M. An experimental study on stability and thermal conductivity of water/silica nanofluid: eco-friendly production of nanoparticles. J Clean Prod. 2019;206:1089-110.

10. Akhgar A, Toghraie D. An experimental study on the stability and thermal conductivity of water-ethylene glycol/ $/ \mathrm{TiO}_{2}$-MWCNTs hybrid nanofluid: developing a new correlation. Powder Technol. 2018;338:806-18.
11. Abbasi S, Zebarjad SM, Baghban SHN, Youssefi A, EkramiKakhki MS. Experimental investigation of the rheological behaviour and viscosity of decorated multi-walled carbon nanotubes with $\mathrm{TiO}_{2}$ nanoparticles/water nanofluids. J Therm Anal Calorim. 2016;123:81-9.

12. Esfe MH, Saedodin S, Asadi A, Karimipour A. Thermal conductivity and viscosity of $\mathrm{Mg}(\mathrm{OH})_{2}$-ethylene glycol nanofluids. J Therm Anal Calorim. 2015;120:1145-9.

13. Kole M, Dey TK. Investigation of thermal conductivity, viscosity, and electrical conductivity of graphene based nanofluids. J Appl Phys. 2013;113:084307-1-8.

14. Omrani AN, Esmaeilzadeh E, Jafari M, Behzadmehr A. Effects of multi walled carbon nanotubes shape and size on thermal conductivity and viscosity of nanofluids. Diam Relat Mater. 2019;93:96-104.

15. Rudyak VY, Krasnolutskii SL. Dependence of the viscosity of nanofluids on nanoparticle size and material. Phys Lett A. 2014;378:1845-9.

16. Wang L, Wang Y, Yan X, Wang X, Feng B. Investigation on viscosity of $\mathrm{Fe}_{3} \mathrm{O}_{4}$ nanofluid under magnetic field. Int Commun Heat Mass Transf. 2016;72:23-8.

17. Yang J, Zhao N, Li Z, Sun A. A combined theory model for predicting the viscosity of water-based Newtonian nanofluids containing spherical oxide nanoparticles. J Therm Anal Calorim. 2019;135:1311-21.

18. Hajiyan M, Ebadi S, Mahmud S, Biglarbegian S, Abdullah H. Experimental investigation of the effect of an external magnetic field on the thermal conductivity and viscosity of $\mathrm{Fe}_{3} \mathrm{O}_{4}$-glycerol. J Therm Anal Calorim. 2019;135:1451-64.

19. Azizian R, Doroodchi E, Mckrell T, Buongiorno J, Hu LW, Moghtaderi B. Effect of magnetic field on laminar convective heat transfer of magnetite nanofluids. Int J Heat Mass Transf. 2014;68:94-109.

20. Nadooshan AA, Eshgarf H, Afrand M. Measuring the viscosity of $\mathrm{Fe}_{3} \mathrm{O}_{4}$-MWCNTs/EG hybrid nanofluid for evaluation of thermal efficiency: Newtonian and non-Newtonian behaviour. J Mol Liq. 2018;253:169-77.

21. Moffat RJ. Describing the uncertainties in experimental results. Exp Therm Fluid Sci. 1988;1:3-17.

22. Kestin J, Sokolov M, Wakeham WA. Viscosity of liquid water in the range $-8^{\circ} \mathrm{C}$ to $150{ }^{\circ} \mathrm{C}$. J Phys Chem Ref Data. 1978;7:941-8.

23. Kim J, Lawler DF. Characteristics of zeta potential distribution in silica particles. Bull Korean Chem Soc. 2005;26:1083-9.

24. Wang J, Li G, Zhu H, Luo J, Sundén B. Experimental investigation on convective heat transfer of ferrofluids inside a pipe under various magnet orientations. Int J Heat Mass Transf. 2019;132:407-19.

25. Sundar LS, Singh MK, Sousa ACM. Investigation of thermal conductivity and viscosity of $\mathrm{Fe}_{3} \mathrm{O}_{4}$ nanofluid for heat transfer applications. Int Commun Heat Mass Transf. 2013;44:7-14.

26. Goharkhah M, Ashjaee M, Shahabadi M. Experimental investigation on convective heat transfer and hydrodynamic characteristics of magnetite nanofluid under the influence of an alternating magnetic field. Int J Therm Sci. 2016;99:113-24.

27. Diao YH, Zhang CZLJ, Zhao YH, Kang YM. Experimental investigation of MWCNT-water nanofluids flow and convective heat transfer characteristics in multiport minichannels with smooth/ micro-fin surface. Powder Technol. 2017;305:206-16.

28. Garbadeen ID, Sharifpur M, Slabber JM, Meyer JP. Experimental study on natural convection of MWCNT-water nanofluids in a square enclosure. Int Commun Heat Mass. 2017;88:1-8.

29. Hosseinian A, Isfahani AHM, Shirani E. Experimental investigation of surface vibration effects on increasing the stability and heat transfer coeffcient of MWCNTs-water nanofluid in a flexible double pipe heat exchanger. Exp Therm Fluid Sci. 2018;90:275-85. 
30. Bandyopadhyaya R, Nativ-Roth E, Regev O, Yerushalmi-Rozen R. Stabilization of Individual carbon nanotubes in aqueous solutions. Nano Lett. 2002;2:25-8.

31. Yu W, Xie H. A review on nanofluids: preparation, stability mechanisms, and applications. J Nanomater. 2012;2012:1-17.

32. Sohn CW, Chen MM. Microconvective thermal conductivity in disperse two-phase mixtures as observed in a low velocity couette flow experiment. J Heat Transf. 1981;103:47-51.

33. Einstein A. Investigations on the theory of the Brownian movement. New York: New York Dover Publications; 1956.
34. Batchelor GK. The effect of Brownian motion on the bulk stress in a suspension of spherical particles. J Fluid Mech. 1977;83:97-117.

35. Brinkman HC. The viscosity of concentrated suspensions and solutions. J Chem Phys. 1952;20:571-81.

Publisher's Note Springer Nature remains neutral with regard to jurisdictional claims in published maps and institutional affiliations. 